\title{
Bevacizumab/Everolimus Regimen
}

National Cancer Institute

\section{Source}

National Cancer Institute. Bevacizumab/Everolimus Regimen. NCI Thesaurus. Code C154269.

A regimen consisting of bevacizumab and everolimus that can be used for the treatment of kidney cancer. 